Percepção espacial da violência e do medo pelos moradores dos bairros Morumbi e Luizote de Freitas em Uberlândia/MG

Márcia Andréia Ferreira Santos, Julio Cesar de Lima Ramires

\title{
PERCEPÇÃO ESPACIAL DA VIOLÊNCIA E DO MEDO PELOS MORADORES DOS BAIRROS MORUMBI E LUIZOTE DE FREITAS EM UBERLÂNDIA/MG
}

\section{Space perception of violence and fear of the residents of neighborhoods Morumbi and Luizote de Freitas in Uberlândia/MG}

\author{
Márcia Andréia Ferreira Santos \\ Doutoranda do Programa de Pós-Graduação em Geografia \\ Universidade Federal de Uberlândia \\ Uberlândia/MG - Brasil \\ karamby@yahoo.com.br \\ Dr. Julio Cesar de Lima Ramires \\ Professor do Instituto de Geografia - UFU \\ Universidade Federal de Uberlândia \\ Uberlândia/MG - Brasil \\ ramires_julio@yahoo.com.br
}

Artigo recebido para publicação em 11/07/2008 e aceito para publicação em 13/02/2009

RESUMO: $\quad$ Objetivou-se a analisar a percepção espacial que os moradores dos bairros Luizote de Freitas e Morumbi têm da violência e do medo; e a partir de entrevistas constatou-se que os homicídios, o tráfico de drogas e os roubos são os crimes que causam mais temor à população. Além disso, muitos moradores afirmaram que temem trafegar por ruas cuja iluminação é ineficiente, ou que apresentem um baixo número de pessoas circulando. Muitos moradores declararam que sentem a falta de atuação da segurança pública no local, fator este que os levam a desenvolver uma ansiedade maior no que se refere à criminalidade violenta no bairro. Constatou-se que, em ambos os bairros há uma preocupação com relação aos espaços vazios, já que eles apresentam características que facilitam a atuação de infratores. Percebeu-se, ainda, que para eles, a ausência da segurança pública, ou seja, a ausência de policiamento ostensivo no bairro auxilia na presença dos transgressores no local. Vale ressaltar que a percepção espacial é um fenômeno individual, que difere em intensidade e modo de expressão, mas quando uma comunidade mantém laços de solidariedade com o lugar por ela ocupado, o sentimento para com o mesmo torna-se um fator coletivo, pois o valor que se atribui ao lugar torna-se unívoco. Conclui-se que os moradores são os principais sujeitos para falar sobre o espaço no qual habitam, pois eles vivem tais espaços cotidianamente e, portanto, se constituem como parte viva dele.

Palavras-chave: Percepção. Medo. Homicídio. Violência. Drogas.

ABSTRACT: The objective is to analyze the spatial perception that the residents of neighborhoods Luizote de Freitas and Morumbi have the violence and fear, and from interviews it was found that the homicide, drug trafficking and theft are crimes that cause most fear the population. Furthermore, many residents said they fear traffic for street lighting which is inefficient, or that have a low number of people moving. Many residents said they feel the lack of performance of public security on site, this factor that leads to 
Percepção espacial da violência e do medo pelos moradores dos bairros Morumbi e Luizote de Freitas em Uberlândia/MG Márcia Andréia Ferreira Santos, Julio Cesar de Lima Ramires

developing a greater anxiety in regard to violent crime in the neighborhood. It was found that in both districts is a concern with respect to the empty spaces, as they have characteristics that facilitate the activities of offenders. It was noticed also that for them, the lack of public safety, or the ostensible lack of police presence in the neighborhood helps the offenders on the spot. It is noteworthy that spatial perception is an individual phenomenon, which differs in intensity and mode of expression, but when a community maintains ties of solidarity with the place occupied by it, the feeling to it becomes a collective factor, because the value that gives the place becomes unambiguous. It is concluded that the residents are the main subject to talk about the space in which live, because they live such spaces daily and therefore are constituted as part of it alive.

Key words: Perception. Fear. Murder. Violence. Drugs.

\section{Introdução}

Tuan $(2005$, p. 231) afirma que "A cidade representa a maior aspiração da humanidade em relação a uma ordem perfeita e harmônica, tanto em sua estrutura arquitetônica como nos laços sociais". Mas durante a sua história "[...] a cidade tem sido oprimida pela violência e pela ameaça constante do caos". (Ibid., p. 251).

Os efeitos da criminalidade violenta sobre o espaço geográfico são marcantes, e dentre eles o medo tem sido a principal causa do isolamento social e do crescimento e continuidade do individualismo, consequências do sentimento de insegurança. Teixeira e Porto (1998) comentam que o imaginário do medo, nas sociedades modernas, bem como o tratamento inadequado da violência pode estabelecer condições que contribuam para o desenvolvimento desse imaginário. A mídia, por exemplo, além de informar, contribui para o aumento do imaginário do medo, ao noticiar ocorrências de atos violentos que se dão com frequência em determinados espaços urbanos.

A crescente violência registrada em Uberlândia se distribui de forma diferenciada no espaço urbano, e tem provocado nos habitantes, sobretudo dos bairros com o maior registro de ocorrências de eventos violentos, um medo real ou imaginário, que se fortalece, não apenas com o aumento dos atos violentos, como também pelos noticiários televisivos. Portanto, o objetivo deste trabalho é apresentar, por meio da fala dos moradores dos bairros Luizote de Freitas e Morumbi, como eles veem e sentem a violência urbana.

\section{Discussão Teórico-Metodológica}

Para a realização deste artigo foram feitos os seguintes procedimentos metodológicos: 1) Levantamento bibliográfico da temática em questão; 2) Pesquisa qualitativa, pautada em entrevistas focalizadas (GIL, 1999), cujo tema específico baseouse nos vocábulos "violência" e "medo". Tais entrevistas foram realizadas em 2005, respectivamente com 15 moradores para cada um dos bairros escolhidos para a análise. A maioria deles eram do sexo feminino, tinham mais de 20 anos, residia no bairro há mais de cinco anos e se ocupavam de serviços sobretudo domésticos e/ou gerais.

A entrevista, conforme Gil (1999, p. 117 apud SELLTIZ et al 1967, p. 273) é uma técnica de coleta de dados que o entrevistador utiliza para obter " [...] informações acerca do que as pessoas sabem, creem, esperam, sentem ou desejam, pretendem fazer, fazem ou fizeram, bem como acerca das suas explicações ou razões das coisas precedentes". Assim, utilizouse esta técnica de pesquisa com o objetivo de verificar a percepção que os moradores dos bairros Luizote de Freitas e Morumbi tinham acerca da violência e do medo. É importante acrescentar que as entrevistas selecionadas para serem utilizadas no artigo foram transcritas com as mesmas palavras empregadas pelo

Sociedade \& Natureza, Uberlândia, 21 (1): 131-145, ABR. 2009 
Percepção espacial da violência e do medo pelos moradores dos bairros Morumbi e Luizote de Freitas em Uberlândia/MG Márcia Andréia Ferreira Santos, Julio Cesar de Lima Ramires

entrevistado, e evitou-se parafrasear as respostas.

Os moradores dessas áreas de risco representam o principal objeto de pesquisa qualitativa sobre a violência, já que eles, tal como afirma Christofoletti (1982, p. 22), encontram-se ambientados e integrados ao lugar no qual habitam; lugar este que se torna parte do seu mundo, "[...] dos seus sentimentos e afeições" sendo, portanto, o seu centro de significância. Dessa forma, eles são capazes de sentir com sensibilidade o lugar onde residem, e perceberem como se dão as mudanças na configuração da paisagem e no comportamento das demais pessoas que habitam o mesmo espaço. Mudanças que a violência se encarrega de trazer, como toda a aparelhagem de segurança instalada nas residências: muros altos, cercas elétricas, grades nas janelas.

Segundo Morais (1990, p. 12)

[...] o medo é o pão cotidiano dos cidadãos. As casas não mais expõem suas fachadas românticas, pois cercam-nas muros muito altos [...]. A pessoas trafegam em seus automóveis com os vidros bem fechados para evitar abordagens perigosas em cruzamentos e semáforos e, dependendo de por onde andem à pé, sentem-se como se estivessem em plena prática da 'roleta russa' [...]. E em parte alguma há segurança.

Assim sendo, vivemos um momento na história em que não há segurança nem mesmo dentro de nossas próprias casas, pois a violência tem invadido todos os espaços da sociedade, inclusive aqueles dos quais acreditávamos ter domínio. É uma realidade sufocante e, ao mesmo tempo, estressante, principalmente para os moradores das grandes cidades brasileiras. Não temos mais prazer como tínhamos outrora quando vamos nos divertir na praia ou em qualquer outro lugar público, pois estamos, a todo instante, olhando para os lados, com medo de sermos, de alguma forma, vítima da violência urbana.

Medo ou sensação de insegurança são palavras presentes no vocabulário dos moradores das grandes cidades brasileiras. Medo de frequentar determinados espaços, e de circular pelas ruas, limitando-se a certos lugares e horários específicos. Varela (2006) chega a afirmar que o medo do crime se constitui num problema maior do que o próprio delito, na medida em que os temores à criminalidade, diferentemente da criminalidade real, afetam em maior quantidade os cidadãos, com consequências permanentes e severas. O medo do delito, segundo essa autora, constitui-se, por si mesmo, um campo de indagação científica, tanto como objeto de regulação por parte das políticas públicas, quanto pelos estudos vitimológicos.

O medo da violência, segundo estudo feito pelo Núcleo de Estudos da Violência (NEV), da Universidade de São Paulo, pode provocar uma série de distúrbios nos moradores das grandes cidades. $\mathrm{O}$ medo da violência urbana pode agir na mente e no corpo das pessoas, desencadeando distúrbios mentais, que vão de neurose e paranóia a síndrome do pânico e, como consequência, causa até transtornos físicos, como úlcera, taquicardia, hipertensão e tensão muscular, queda da resistência e aumento de quadros infecciosos. (OLIVEIRA, 2004; SOUZA, 2008). Há, portanto, uma relação direta entre medo da violência e doenças psicóticas e físicas. O sociólogo Michel Misse, coordenador do Núcleo de Estudos da Cidadania, Conflito e Violência Urbana da Universidade Federal do Rio de Janeiro (UFRJ) acrescenta que, além de tudo isso, o excesso de informação violenta é responsável por gerar, também, medo e neuroses urbanas, pois as pessoas têm acesso à informação sem experimentar a situação, pois existe a diferença entre a percepção real, que é como a realidade é interpretada, e a violência real.

Teixeira e Porto (1998) acrescentam que as consequências advindas do medo caracterizam-se, também, por dois aspectos: 1) Modifica as relações sociais, fazendo de cada indivíduo uma vítima real ou potencial, ou um suspeito permanente, desenvolvendo formas de solidariedade e identificação ou colocando uns contra os outros; 2) Cria novos lugares de encontro, de sociabilidades. Concomitante a esse fenômeno, há um fortalecimento das redes comunitárias de solidariedade, como 
Percepção espacial da violência e do medo pelos moradores dos bairros Morumbi e Luizote de Freitas em Uberlândia/MG Márcia Andréia Ferreira Santos, Julio Cesar de Lima Ramires

tentativa de resistência à redução dos espaços sociais de convivência mútua.

Tuan (1988, p. 114) comenta que uma pessoa, "[...] no transcurso do tempo, investe parte de sua vida emocional em seu lar, em seu bairro". A partir disso, constata-se que os laços afetivos que um ser humano mantém com o local no qual habita é muito forte, e que tais laços, quando ameaçados, tendem a levar a população à busca de situações que revertam o quadro, pois, segundo o autor supracitado, “[...] a saúde da sociedade depende da frequência de atos amistosos e do sentimento de associação comunitária". (Ibid, p. 242).

Para Tuan (2005, p. 336) “[...] o medo foi e é uma razão comum para tecer estreitos laços entre as pessoas. Removidas as ameaças do meio ambiente, quer sejam as forças da natureza, quer inimigos humanos, a união da comunidade tende a enfraquecer". Para exemplificar, o referido autor comenta que tanto em Roma ou Florença medieval "[...] existia uma forte lealdade em cada bairro protegido [...] mas os laços eram forjados pela necessidade e pelo medo". (Ibid., p. 336). E acrescenta que "[...] desde a família até a nação-estado, os laços comunais podem aumentar ou diminuir com o medo". (Ibid., p. 337). Pensando dessa forma, pode-se chegar à conclusão de que o medo funciona como um fator positivo no sentido de manter a coesão entre as pessoas próximas, com vistas à busca de proteção para si e para o lugar no qual habitam.

Em se tratando do medo nos dias atuais, uma pesquisa realizada em 2002 pela Fundação Getúlio Vargas (FGV) revelou que nove capitais do Brasil apontaram que o medo acentua-se nas cidades grandes e médias, e que os pobres e as mulheres são quem mais sofrem com o medo. Como exemplo, a cidade de Belo Horizonte se destacou entre as mais "medrosas" do país. Através do índice do medo, que mede a percepção da insegurança, em escala de $0 \mathrm{a}$ 100 pontos, Belo Horizonte, Fortaleza e Curitiba estão empatadas em segundo lugar no ranking, com 61 pontos, perdendo apenas para Salvador, Porto Alegre e São Paulo, empatadas em primeiro lugar com 62 pontos. A média brasileira é de 48 pontos.

Entrevistas realizadas em Belo Horizonte mostraram que roubo à mão armada, arrombamento de casa e latrocínio estão entre os crimes que causam mais medo à população. Outra consequência direta dos eventos violentos é a mudança de hábito dos moradores. Em Belo Horizonte, por exemplo, a pesquisa supracitada constatou que as situações mais temidas pelos moradores são: andar em locais e bairros desconhecidos, e, sobretudo, após as 22 horas, sair de casa nos finais de semana, andar sozinho nas ruas, sair de casa durante o dia e andar no próprio bairro. Para estes, como para a maioria da população citadina, "A violência pulsa desde o amanhecer para aquele que incorporou o medo como cultura da metrópole". (PEDRAZZINI, 2006, p. 24).

Mas a violência, que por sua vez gera o medo, nada mais é do que a aplicação da força para o exercício do poder de alguém contra outro indivíduo, grupos, ou contra si mesmo, com intenção de provocar dano físico (LOPEZ et al., 1992, MORAIS, 1990). Arendt (1985, p. 19) afirma que "[...] a violência nada mais é do que a mais flagrante manifestação de poder. [...] o tipo de poder mais definitivo é a violência", e acrescenta que

Se a essência do poder é a efetividade do domínio, não existe então nenhum poder maior do que aquele que provém do cano de uma arma, e seria difícil dizer "de que maneira a ordem dada por um policial é diferente daquela dada por um bandido armado". (ARENDT, 1985, p. 20).

Assim, tanto o poder quanto a força, a autoridade ou a violência, para a autora supracitada, nada mais são do que palavras para indicar os meios pelos quais o homem governa o seu semelhante. Poder e violência são fenômenos distintos, mas geralmente se apresentam juntos. Arendt (1985, p. 28) declara que "À violência sempre é dado destruir o poder; o cano de uma arma desponta o domínio mais eficaz, que resulta na mais perfeita e imediata obediência. $\mathrm{O}$ que jamais poderá florescer da violência é o poder". Dessa forma, "A violência pode destruir o poder, mas 
Percepção espacial da violência e do medo pelos moradores dos bairros Morumbi e Luizote de Freitas em Uberlândia/MG Márcia Andréia Ferreira Santos, Julio Cesar de Lima Ramires

é incapaz de criá-lo", (Ibid., p. 31), uma vez que à violência cabe a submissão, mediante o domínio de outrem. E, além disso, “[...] toda diminuição de poder é um convite à violência". (Ibid., p. 49). Nesse sentido, Baierl (2004, p.37) afirma que "O medo tem sido utilizado como estratégia de manipulação para subjugar, controlar escravizar e dominar as pessoas. Frente às situações de uso do medo, as pessoas se sentem aterrorizadas, fogem do perigo ou se entregam".

Por outro lado, Chesnais (1999) afirma que a violência ao gerar o medo, gera, igualmente, violência; e acrescenta que os únicos beneficiados são certos lobbies da segurança, como as firmas de vigilância, as milícias privadas e as companhias de seguros. Portanto, o medo torna-se consequência direta da crescente violência. É um medo que, além de alterar o comportamento da população, modifica, também, as formas urbanas. Felix (2002) confirma o que foi dito quando argumenta que tanto o medo quanto a necessidade de proteção refletem nas diversas formas de aproveitamento do espaço e transformam o desenho da paisagem urbana. E, ainda:

[...] o medo tanto pode inibir ações cooperativas contra o crime quanto encorajar estratégias individualistas em nível residencial. A utilização de animais em residências, o design de certas construções (grades de proteção, muros altos, vitrôs pequenos e altos etc.), a criação de guardas particulares, a manutenção de luzes acesas no interior das casas, o surgimento de bairros fechados etc., são positivamente relacionados com o medo do crime. A exploração deste medo e a ansiedade da população são visíveis em diversos setores e explorado das mais diversas formas, que vão desde o marketing político (eleitoreiro) até o financeiro (imobiliário). Atualmente os anúncios de compra e venda de imóveis estão dando maior destaque à segurança do que ao próprio conforto habitacional (FELIX, 2002, p. 129).

Como consequência disso, o "mercado de segurança", tal como afirma Felix (2002, p. 130), cresce de $30 \%$ a $40 \%$ ao ano, e tende a acelerar-se ainda mais, uma vez que o "[...] o medo e a insegu- rança estão crescendo mais que os índices criminais (há quem afirme que enquanto o crime aumenta em progressão aritmética, o medo cresce em progressão geométrica)". Assim, Francisco Filho (2004) afirma que a violência e o medo participam, cada vez mais, dos temores de quem habita as cidades, proporcionando um comportamento no qual o medo ocupa o topo de suas inquietações. Nas palavras deste autor,

Viver a cidade, hoje, é viver o medo, a incerteza de chegar em casa ao final do dia; se nossos filhos voltam ilesos depois de se aventurarem pela cidade, seja em busca de divertimento, ou de conhecimento. Conhecer essa realidade, entender como esse processo nasce, se desenvolve e se espacializa nas nossas metrópoles é de grande importância, pois sem isso estaremos fadados a viver em espaços cada vez mais segregados, fechados dentro de uma realidade que não vai além dos muros e das cercas eletrificadas (FRANCISCO FILHO, 2004, p. 1).

Dessa forma, Souza $(2008$, p. 8$)$ afirma que a "[...] violência e a insegurança chegaram ao ponto de influenciar decisivamente a vida diária, os padrões de circulação no espaço e mesmo o habitat e as formas espaciais". O referido autor afirma que há um entrecruzamento entre medo e cidade, formando o que ele chama de "fobópole", a "cidade do medo", ou seja, "[...] uma cidade dominada pelo medo da criminalidade". (Ibid., p. 9). Assim, tanto o medo quanto a violência "[...] vêm cada vez mais se apresentando como fatores de condicionamento das relações sociais e de modelagem do espaço nas cidades". (Ibid., p. 13). Mas outros fatores como a mídia tende a ampliar e a alimentar o medo entre as pessoas por meio da linguagem que utilizam em reportagens sobre a violência. Com isso, "Em uma fobópole $[\ldots]$ o medo do crime encontra [...] um terreno fértil para continuar prosperando". (Ibid., p. 30)

A manifestação espacial do crime, segundo Felix (2003, p. 1) "[...] altera valores e percepções espaciais, deteriora os espaços urbanos, altera os níveis de concentração ou esvaziamento e cria espaços do medo". Muitos espaços citadinos deixam de ser 
Percepção espacial da violência e do medo pelos moradores dos bairros Morumbi e Luizote de Freitas em Uberlândia/MG Márcia Andréia Ferreira Santos, Julio Cesar de Lima Ramires

utilizados pela população porque o medo de práticas violentas, muitas vezes imaginárias, desencadeia um sentimento de insegurança, que impede a apropriação dos mesmos. Por esse motivo, “[...] vários tipos de interação espacial diminuem (e até tendem a desaparecer) ou tornar-se (muito) mais seletivos". (SOUZA, 2008, p. 58). Acrescenta-se, dessa forma, que o medo da violência cria e reforça exclusões e auto-exclusões, em que "Espaços públicos vão sendo [...] ou abandonados [...] ou, então, 'cercados e monitorados'." (Ibid., p. 84). Mas para o referido autor, "A auto-segregação é uma solução escapista. Representa uma fuga e não um enfrentamento, muito menos um enfrentamento construtivo". (Ibid., p. 73).

Constata-se, portanto, que a violência, real ou imaginária, redefine o modo de vida das pessoas que habitam a cidade. (FELIX, 2003; SORIANO, 2007; SOUZA, 2008). Assim, "O ritmo da cidade determina o ritmo da vida, contaminando as relações sociais" (CARLOS, 2004, p. 42). Tais mudanças são visíveis na cidade de São Paulo, uma das mais violentas do Brasil. Caldeira (2003) diz que o aumento dos crimes violentos na capital paulista ocorreu concomitante ao crescimento do sentimento de medo, que proporcionou uma mudança na vida cotidiana da população daquela cidade:

A vida cotidiana e a cidade mudaram por causa do crime e do medo, e isso se reflete nas conversas diárias, em que o crime tornou-se um tema central. $\mathrm{Na}$ verdade, medo e violência, coisas difíceis de entender, fazem o discurso proliferar e circular. A fala do crime-ou seja, todos os tipos de conversas, comentários, narrativas, piadas, debates e brincadeiras que têm o crime e o medo como tema - é contagiante. [...]. O medo e a fala do crime não apenas produzem certos tipos de interpretações e explicações, habitualmente simplistas e estereotipadas, como também organizam a paisagem urbana e o espaço público, moldando o cenário para as interações sociais que adquirem novo sentido numa cidade que progressivamente vai se cercando de muros. A fala e o medo organizam as estratégias cotidianas de proteção e reação que tolhem os movimentos das pessoas e restringem seu universo de interações. (CALDEIRA, 2003, p. 27)

Com base na fala supracitada, Cardia (2003) comenta que se as leis e a polícia são percebidas como falhando em dar a sensação de proteção. Além disso, ela diz que a exposição à violência provoca muito medo, e quanto maior for essa exposição e a gravidade da violência a qual estão expostos, maior é o impacto. Como consequência, o medo se generaliza e passa a afetar o modo como as pessoas usam a cidade. Isto inclui as ruas do bairro onde vivem, quer seja dia ou noite. Ter medo de caminhar por ruas do próprio bairro é um sinal de alerta quanto à intensidade do medo. $\mathrm{E}$ acrescenta que

A forte exposição à violência mais grave provoca não só mais medo entre aqueles mais expostos, mas também afeta seus comportamentos e sua disposição em investir para garantir maior segurança. As diferenças entre quem está mais exposto e quem está menos exposto não se limita a adoção de equipamentos de segurança mas se estende a mudanças de comportamentos como o medo de andar por ruas ou bairros.[...] O mesmo se passa com a decisão de mudar o trajeto da casa para a escola ou o trabalho e a vontade de evitar o uso de certas linhas de ônibus. O maior medo também encoraja o maior isolamento dos vizinhos: deixar de conversar com vizinhos, ou proibir filhos de brincarem com crianças da vizinhança também é muito superior entre aqueles mais expostos à violência. (CARDIA, 2003, p. 316).

Feiguin (1995) trabalha o conceito de "arquitetura do medo" para explicar que as cidades têm assumido feições que refletem o sentimento de insegurança e medo vivido pela população citadina:

[...] muros altos, cercas ao redor das casas, proliferação de sofisticados sistemas de segurança e alarme, crescimento visível das empresas privadas de vigilância, aumento do número de portes e registros de armas concedidos à população, fuga de zonas e regiões onde o risco de se transitar sozinho de dia e, principalmente, a 
Percepção espacial da violência e do medo pelos moradores dos bairros Morumbi e Luizote de Freitas em Uberlândia/MG Márcia Andréia Ferreira Santos, Julio Cesar de Lima Ramires

noite é bastante elevado, além de vários outros mecanismos de autoproteção. (FEIGUIN, 1995, p. 73).

Caldeira (1997) discute a questão da formação dos condomínios fechados em São Paulo, ou como ela mesma os chama de "enclaves fortificados", sob a perspectiva do aumento da violência. A autora faz uma análise da disseminação desses espaços privados, fechados e monitorados para residência, consumo, lazer ou trabalho que, em função do medo e da insegurança provocada pela elevação dos atos violentos, vêm atraindo as classes média e alta em São Paulo. A autora investiga, sobretudo, uma autosegregação urbana induzida, principalmente, pelas consequências da crescente disseminação da violência naquela metrópole. Mas essa auto-segregação é um processo que tem sido observado não somente nas metrópoles, mas vem se intensificando nas cidades de porte médio, e a formação de um condomínio, bem como o apelo por se morar em um deles vem sempre arraigado à questão do aumento da criminalidade e à busca de segurança.

Conforme Baierl (2004, p.20), o medo construído socialmente tem alterado "[...] o tecido urbano e, consequentemente, a vida cotidiana da população. Todos se sentem afetados, ameaçados e correndo perigo". Para a referida autora, "[...] buscar explicar as formas como crescem e se desenvolvem o medo social e a violência urbana exige contextualizalas social, histórica e cotidianamente." Compreender, portanto, as modificações que ocorrem na configuração espacial de um determinado local em decorrência do medo, bem como entender como se dá esse fenômeno, e em que medida ele se torna um fator diretamente proporcional à violência, é uma questão que exige muito esforço. A análise espacial da cidade de Uberlândia, bem como as entrevistas realizadas nos bairros Morumbi e Luizote de Freitas comprovaram o que as teorias afirmam com relação a esse fenômeno, sobretudo no que se refere às mudanças espaciais, ao surgimento dos condomínios, às mudanças de comportamento, dentre outros. E é sobre isso que trataremos a seguir.

\section{Caracterização da área de estudo}

O bairro é uma unidade espacial que, conforme Cearteau, Giard e Mayoul (1993, p. 43) “'[...] é o espaço de uma relação com o outro como ser social". Em outras palavras, é o lugar no qual as pessoas se encontram ligadas entre si por meio da proximidade e da repetição. Por este motivo, Melgaço (2005) afirma que dificilmente uma pessoa comete um crime no local onde mora.

Os bairros Luizote de Freitas e Morumbi localizam-se, respectivamente, nos extremos do Setor Oeste e Leste de Uberlândia (Cf. Mapa 1). São bairros que têm em comum a sua origem como conjuntos habitacionais financiados pelo poder público em diferentes momentos da estruturação do seu espaço urbano.

A localização dos mesmos nos pontos extremos da cidade de Uberlândia facilita a fuga dos criminosos, pois as rodovias que passam próximas aos mesmos dão acesso a outros municípios de Minas Gerais, bem como à zona rural.

O Luizote de Freitas, antes denominado Conjunto Habitacional Luizote de Freitas foi construído a partir de 1979, e destinou-se à população de baixa renda. Na época, sua localização encontravase fora do perímetro urbano, distando $7 \mathrm{Km}^{2}$ da área urbana. O conjunto tornou-se, um dos mais importantes da cidade.

Soares e Moura (2000) comentam que o referido conjunto era composto por cinco tipos de residências: embrião (com $\left.21,84 \mathrm{~m}^{2}\right)$; casa 2 (com $36,59 \mathrm{~m}^{2}$ e dois quartos); casa 3 (com 43,79 $\mathrm{m}^{2}$ e três quartos); casa 4 (com 50,51 $\mathrm{m}^{2}$ ) e quatro quartos; e sobrado (com $46 \mathrm{~m}^{2}$ e dois quartos. Atualmente, essas moradias encontram-se, em sua maioria, transformadas, abrigando um conteúdo social de maior renda. Em 2007, conforme dados do IBGE, o bairro Luizote de Freitas possuía 22.594 habitantes. 
Percepção espacial da violência e do medo pelos moradores dos bairros Morumbi e Luizote de Freitas em Uberlândia/MG Márcia Andréia Ferreira Santos, Julio Cesar de Lima Ramires

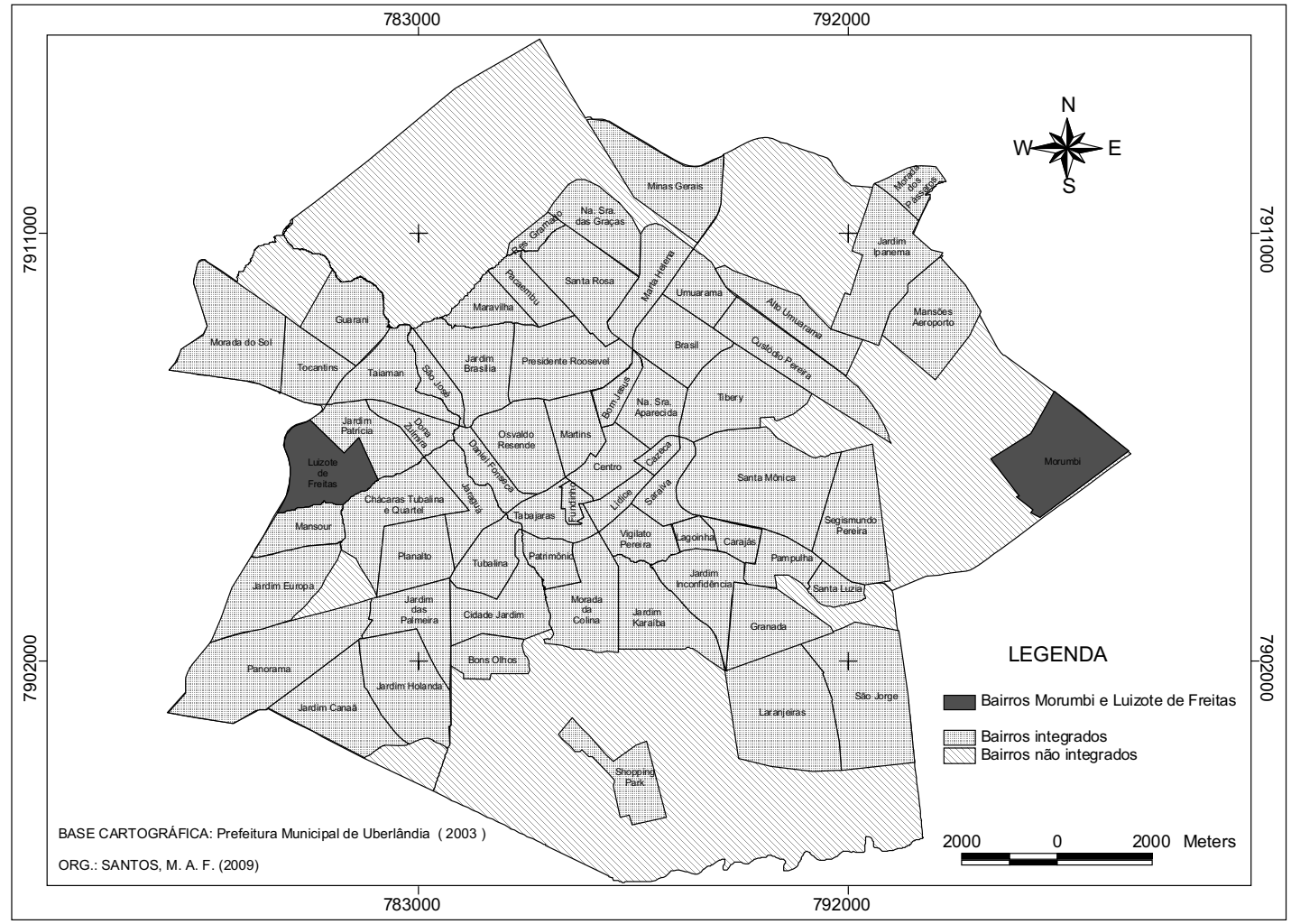

Mapa 1. Cidade de Uberlândia. Localização dos bairros Luizote de Freitas e Morumbi.

A avenida José Fonseca e Silva é a principal do bairro, onde se concentram as atividades de comércio e serviços, que o tornaram um dos mais importantes subcentros da cidade, servindo como ponto de referência para os bairros localizados no seu entorno. Contudo, as áreas de lazer são escassas, havendo apenas duas praças e um poliesportivo.

Soares (1988) constatou, já na década de 1980, que a violência era uma das principais preocupações dos moradores, e no jornal Primeira Hora noticiava que "O Luizote é um caso de polícia. Há casos de banditismo, os moleques quebram lâmpadas da rua, os desocupados assaltam armazéns e as pessoas. O policiamento é escasso, devido ao tamanho". (PRIMEIRA HORA, 1981 apud SOARES, 1988). A referida autora ainda ressalta que as taxas mais elevadas de criminalidade no Luizote de Freitas estavam relacionadas ao tráfico de drogas, praticado principalmente por crianças e adolescentes.
O Morumbi, antes denominado Conjunto Santa Mônica II, surge no início da década de 1990, e era composto por três loteamentos integrados em 1995. Sua construção foi destinada a população de baixa renda e era formado por casas com $23 \mathrm{~m}^{2}$. E, como afirma Araújo Sobrinho (1995), a sua construção teve como objetivo central, a expansão do perímetro urbano em direção a área rural do município, incorporando novos espaços à cidade e, alimentando o processo de especulação imobiliária.

Araújo Sobrinho (1995) realizou entrevistas com moradores do bairro, e constatou que a violência era apresentada como o principal problema, vindo antes de questões relacionadas à educação e o transporte. $\mathrm{O}$ autor comenta que, logo no início da estruturação do conjunto habitacional, foram registrados atos violentos, tais como depredações de ônibus e do patrimônio público, assaltos, tentativas de estupro e uso de drogas, e a atuação da polícia era pontual. 
Percepção espacial da violência e do medo pelos moradores dos bairros Morumbi e Luizote de Freitas em Uberlândia/MG Márcia Andréia Ferreira Santos, Julio Cesar de Lima Ramires

Em 2007, a população no bairro era de 16.161 habitantes, conforme dados do IBGE, e houve pouca alteração do perfil socioeconômico dos moradores, ainda predominando no local os grupos de baixa renda, um comércio insipiente e uma carência de equipamentos públicos. O entorno do bairro comporta algumas áreas de ocupação irregular, que reforçam a segregação espacial desta área da cidade.

Em função do contexto da violência no Morumbi foi instalado um Posto Integrado de Segurança Pública e Cidadania (PISC), que tem por objetivo prestar serviços de atendimento jurídico, social e psicológico, realizados por policiais militares, assistentes sociais e psicólogos. A instituição desenvolve, também, atividades de lazer e cultura, jornadas de cidadania e educação comunitária.

O bairro também é objeto de implantação de uma política pública estadual de prevenção da violência, o Fica Vivo, que é um programa de prevenção à criminalidade, de caráter comunitário, que atua no estabelecimento de atividades rotineiras de prevenção ao crime por meio de diversos projetos. Ele é desenvolvido em áreas eleitas a partir de indicadores como número de ocorrência, perfil dos homicídios e características socioeconômicas das áreas. Ele atua no sentido de implementar medidas que reduzam os fatores de risco à criminalidade e no fortalecimento de fatores de proteção contra a mesma.

Silveira (2007, p. 141) comenta que o Fica Vivo é um programa comunitário porque as ações implementadas estão voltadas para a comunidade, e são realizadas com e por meio dela, "[...] que tem um papel importante na elaboração de um plano local de segurança pública, na execução de algumas ações e no monitoramento do programa".

Ao realizar as entrevistas com os moradores desses respectivos bairros, com o objetivo de verificar a percepção deles sobre a violência e o medo no lugar onde moram, constatou-se que a sensação de insegurança dos mesmos, vinculada às questões referentes à criminalidade violenta é diretamente proporcional ao número de registros de ocorrências criminais registradas pela Polícia Militar; e é sobre tais entrevistas que falaremos a seguir.

\section{Análise das entrevistas}

Para Tuan (1983) as pessoas que residem num determinado espaço possuem experiências específicas sobre ele, baseadas no conhecimento e na construção que fazem da realidade circundante. Tal experiência, conforme o referido autor, varia "[...] desde os sentidos mais diretos e passivos como o olfato, paladar e tato, até a percepção visual ativa e a maneira indireta de simbolização". (Ibid., p. 9).

A análise das entrevistas apresentou muitos símbolos das experiências vividas e percebidas pelos moradores dos bairros Luizote de Freitas e Morumbi sobre a violência presenciada no local. Na fala dos entrevistados há um léxico categorial de valor semântico vinculado à temática do medo, da insegurança e da violência que denotam o conhecimento que os mesmos possuem do fato. Alguns exemplos de vocábulos como "noite", "escuro", "iluminação", "ataque", "perigo" e "marginal" são constantes nas falas registradas, havendo uma predominância dos três primeiros vocábulos citados.

Com relação ao vocábulo "noite", Tuan (2005, p. 256) comenta que nas cidades medievais "[...] quando a noite se aproximava, os próprios cidadãos reconheciam a necessidade de se recolher para a segurança de seus lares, deixando os becos escuros aos ladrões e aos imprudentes foliões". Em se tratando dos vocábulos "escuro" e "iluminação", o autor supracitado diz que "[...] O crime na Londres do século XVIII era corrente. Após o escurecer os cidadãos relutavam em ir às ruas pouco iluminadas". (Ibid., p. 257). Tais palavras, portanto, exemplificam a forma como os moradores percebem a violência e a insegurança do local onde residem, e como agem diante desse fenômeno buscando protegerem-se. 
Percepção espacial da violência e do medo pelos moradores dos bairros Morumbi e Luizote de Freitas em Uberlândia/MG Márcia Andréia Ferreira Santos, Julio Cesar de Lima Ramires

\subsection{Bairro Luizote de Freitas}

\subsubsection{Medo de trafegar à noite pelo bairro}

Ao analisar as entrevistas realizadas nos bairros Luizote de Freitas e Morumbi, constatou-se que o medo é um fator presente na fala dos moradores destes respectivos bairros. Muitos entrevistados afirmaram que têm medo de circular, à noite, pelas vias públicas, em razão do elevado número de assaltos. Veja o que um dos entrevistados do bairro Luizote de Freitas, aqui chamado Morador 1, disse:

Medo de andar, à noite [...]. Até de dia também eu já fui ameaçado de assalto duas vezes aqui no bairro: uma vez foi onze horas, outra vez era umas seis horas da tarde. Já duas vezes que me atacam aqui. Lugar aqui que é perigoso é o próprio lugar que eu moro que aqui à noite não tem iluminação aqui nessa avenida do bairro. (MORADOR 1 Luizote de Freitas).

Ressalta que uma das causas do medo em trafegar à noite no bairro são as condições estruturais do espaço, tais como o tamanho das árvores e a pouca iluminação de algumas ruas, que acabam impedindo uma melhor visibilidade. Esse entrevistado, que reside próximo ao Córrego do Óleo, onde há uma iluminação ineficiente e uma área de Proteção Permanente, disse:

No fundo do Poli, ali, aquele mangueiral que tem ali, direto tem marginal escondendo ali, fumando droga. [...]. Tinha que passar uma patrolha ali e derrubar aquelas mangueira, que aquilo ali não serve pra nada. [...] Eles esconde ali no fundo do córrego ali. [...] Sê num vê polícia nesse fundo aqui, então ficam à vontade... a rua é escura (MORADOR 1 - Luizote de Freitas).

\subsubsection{Tráfico de drogas}

Quando o Morador 2 foi indagado sobre os principais problemas existentes no bairro, ele destacou a existência de uma quantidade elevada de usuários de droga, bem como a incidência de muitos assaltos. Segundo ele, a ausência da segurança pública no local onde ele mora pode ser a causa do elevado número de crimes registrados. Disse que há pouco policiamento, e isso é um fator de proteção à ação dos bandidos:

Tem muito maconheiro demais... é... tem muito assalto também aqui no bairro. Nesses fundo aqui tem uma desvantagem muito grande aqui... não tem assistência... igual lá pra cima sê vê polícia, sê vê viatura toda hora, aqui não, aqui passou de nove horas da noite... passou da linha do ônibus dali pra baixo sê num vê polícia, sê num vê patrulha, sê num vê ninguém. A gente que mora pra baixo aqui a gente é muito prejudicado em tudo, porque tudo que sê precisa sê tem que ir lá em cima, é farmácia, é supermercado, é tudo. [...] (MORADOR 2 - Luizote de Freitas).

\subsubsection{Homicídios}

Para saber se os moradores tinham conhecimento das ocorrências de homicídios no bairro, foi perguntado se eles sabiam de algum evento criminal dessa natureza no local, e a afirmativa foi que geralmente ocorre, e que a maioria das ocorrências está relacionada à droga. Veja o que o Morador 2 e o Morador 3 disseram, quando questionados sobre os homicídios no bairro:

De vez em quando até que às vezes acontece de ter algum assim, sabe. Às vezes quando eles mata um assim é marginal. De vez em quando eles apaga um, faz uma limpeza dum. A vizinha aqui perdeu um filho, tadinha. Na época não prendeu quem matou, não, mas depois passou um ano mataram ele. É cobra pegando cobra. (MORADOR 2 Luizote de Freitas).

Teve uma época que tinha. Era muito pesada a barra aqui na época, há uns anos atrás... tem um pouco de tempo. Então, teve alguns homicídios. Inclusive teve um que eles mataram debaixo daquela árvore ali [...] lá naquele terreno que tem umas pedras. Mas essa coisa assim de traficante, esses trem deles mesmo. Depois mataram um outro que morava nessa rua. Mataram ele também, mas 
Percepção espacial da violência e do medo pelos moradores dos bairros Morumbi e Luizote de Freitas em Uberlândia/MG Márcia Andréia Ferreira Santos, Julio Cesar de Lima Ramires

foi bebida, porque se ele não quisesse morrer não saísse tarde da noite, nem ia procurar, porque às vezes procura a briga e a morte com a mão, né (MORADOR 3 - Luizote de Freitas).

\subsection{Bairro Morumbi}

\subsubsection{Medo de trafegar à noite}

Quando se questionou aos entrevistados, moradores do Morumbi, se havia algum lugar no bairro que eles tinham medo de circular, a maioria respondeu que sente medo de trafegar pelas ruas do bairro durante a noite porque é bastante perigoso, principalmente porque elas ficam vazias nesse período. Outros afirmaram que algumas ruas ficam escuras por causa das árvores que impedem a iluminação. Vale destacar que um dos entrevistados ressaltou que o patrulhamento no bairro, realizado pela Polícia Militar, diminuiu a ação dos bandidos. Veja as citações a seguir:

Ah, aqui à noite é perigoso. Á noite você não vê ninguém na rua. Todo mundo fica caladinho dentro de casa. Tem muita morte por aí [...] tiro. À noite a gente não sai aqui (MORADOR 2 - Morumbi).

Todo canto. Aqui à noite ninguém arrisca sair depois de onze, doze horas, não. É triste, mas agora deu uma diminuída boa. A polícia tem feito um bom trabalho, sabe. Vez em quando sê vê o patrulhamento rondando. Os bandido se sentiram intimidados depois dessa ação policial aqui no Morumbi (MORADOR 3 -Morumbi).

Eu mesmo não tenho não. Depende de com quem você anda, é. Depende das pessoas do lugar, né. Em alguns lugar no bairro, pelo menos no Morumbi mesmo, em algumas ruas têm muita árvore, né, a rua fica escura (MORADOR 4 Morumbi).

Em todo o bairro, principalmente à noite porque é muito escuro (MORADOR 5 - Morumbi).

\subsubsection{Homicídios}

Quando os moradores foram questionados sobre as ocorrências de homicídios no Morumbi, percebeu-se que eles não estavam muito abertos para falar sobre o assunto. Esta foi uma das questões que eles falaram menos. Simplesmente afirmavam que havia um número elevado de homicídios no bairro, mas que as suas causas estavam voltadas para acertos de contas entre traficantes. Um morador destacou que as pessoas que não se envolvem com a criminalidade não são atingidas no bairro, o que ele chama de "gente direita”. As principais causas desse crime, segundo os entrevistados, são o acerto de contas entre traficantes ou outro fator que esteja relacionado à droga, confira:

Sempre tem (homicídios). Mas é que nem eu tô te falando assim, gente direita, gente

boa não, sabe (Morador 2 - Morumbi).

Teve um homicídio na rua de lá, e na outra, mas é briga entre eles mesmos (traficantes), entendeu? (Morador 4 - Morumbi).

\subsubsection{Tráfico de drogas}

Todos os moradores entrevistados afirmaram que o principal problema presente no bairro Morumbi é a violência, que pode ser entendida como o uso e o tráfico de drogas, homicídios e roubos, fatores que trazem preocupações aos moradores, pois geram o medo devido à sensação de insegurança na qual eles vivem:

As pessoas discrimina aqui muito é a violência, né, e o bairro não tem uma estrutura. [...] O bairro é violento entre eles mesmos (os traficantes), entendeu? [...] Então, o bairro gera a violência é por causa disso (MORADOR 4 - Morumbi).

As drogas é demais aqui... é demais (MORADOR 4 - Morumbi).

Às vezes a gente ouve falar de traficante, tem muito traficante (MORADOR 5 - Morumbi). 
Percepção espacial da violência e do medo pelos moradores dos bairros Morumbi e Luizote de Freitas em Uberlândia/MG Márcia Andréia Ferreira Santos, Julio Cesar de Lima Ramires

\subsubsection{Roubos}

Quando os moradores foram indagados sobre os problemas urbanos existentes e os crimes que geralmente ocorrem, disseram que há muitos ladrões, roubos, estupros, homicídios e drogas são frequentes no Morumbi. Veja algumas falas:

O que mais acontece aqui é os roubo (MORADOR 1 - Morumbi).

A gente vê muito caso, né, de estupro, homicídio, roubo, droga, tá demais, mas isso Uberlândia tá cheio, e não é só aqui não, é em todo o Brasil, todo o mundo. É... tá difícil viu (MORADOR 2 Morumbi).

Ladrão, né. Na minha rua aqui tem uns três ou quatro que tá preso (MORADOR 3 - Morumbi).

\subsubsection{Sentimento de insegurança}

Segundo os entrevistados, a segurança no bairro ainda não é eficaz, sobretudo porque, de acordo com eles, existem muitos roubos no local. Os entrevistados destacaram que há o policiamento preventivo no bairro, mas ainda não é o suficiente. Comentaram, ainda, que o bairro Morumbi já foi bem mais violento do que atualmente, e que, hoje, a criminalidade já diminuiu bastante se comparado com outros momentos. Veja algumas falas:

$\mathrm{Na}$ área de segurança, o Morumbi melhorou muito, que eu conheço o Morumbi desde quando ele começou [...]. Hoje, o Morumbi praticamente às dez da noite, onze horas eu não vejo tanto perigo dependendo do ambiente. O policiamento do bairro você vê as patrulhas fazendo o patrulhamento à noite. [...] Eu acho que o Morumbi, em termos do que ele era, está melhorando aos pouco, mas só que pra ele melhorar mais eu acho que a segurança deveria melhorar mais um pouquinho (MORADOR 2 Morumbi).

Olha, aqui acontece muita coisa que precisa de segurança. Tem muita morte, muito assalto, muita coisa que precisa. A gente não tem que olhar só para a gente, tem que olhar para o ambiente, né. Precisa, precisa de bastante segurança sim. Tem muito roubo, muito assalto aqui no bairro. (MORADOR 3 - Morumbi).

Percebeu-se que os moradores não estavam satisfeitos com a segurança no Morumbi, e então foi feita a pergunta sobre o que poderia ser feito para melhorar a segurança no bairro. Em resposta, sugeriram que o policiamento deveria ser mais frequente nas ruas para intimidar os bandidos. Um morador destacou que deveria haver policiamento nas escolas, pois nelas a violência tem feito muitas vítimas:

No meu ponto de vista, eu acho que os policias deviam passar mais vezes na rua. Devia arrumar um jeito de espantar esse bando de 'mala' que fica aqui pelas ruas. Tem pessoas que até sente medo de passar perto desse tipo de gente, porque não sabe o que pode acontecer. É muito estranho. Eu, por exemplo, tenho receio de sair à noite aqui... eu não sei como é que tá a rua, se tem segurança ou não (MORADOR 1 - Morumbi).

Onde eu acho que deveria ter um policiamento mais ativo, mais trabalhado são nas escolas do bairro. [...]. Eu acho que a patrulha escolar ela tinha que ser mais freqüente (MORADOR 4 Morumbi).

Policiamento, ter mais policiais nas ruas (MORADOR 5 - Morumbi).

\section{Considerações Finais}

O medo, tal como foi discutido neste trabalho, é apenas uma das diversas consequências trazidas pela violência, que a cada dia faz mais vítimas, direta ou indiretamente. Infelizmente, não adianta ficarmos trancados dentro de casa, sob todos os mecanismos físicos de proteção, pois tal conduta não vai inibir o crime, já que ele estende-se, também, para dentro de nossas residências. 
Percepção espacial da violência e do medo pelos moradores dos bairros Morumbi e Luizote de Freitas em Uberlândia/MG Márcia Andréia Ferreira Santos, Julio Cesar de Lima Ramires

Todo o aparato de segurança empreendido pelo Estado ainda não tem sido suficiente para garantir plena paz às pessoas. A sensação de insegurança é algo que não desaparece logo que policiais são postos nas ruas para combaterem o crime. Apesar de muitas estratégias de combate à criminalidade estarem sendo estabelecidas na cidade de Uberlândia, os moradores ainda não se sentem totalmente seguros ao andarem pelas ruas ou trafegarem por ambientes com pouca iluminação e de baixa densidade populacional. Foi isso o que se pôde constatar na fala dos moradores entrevistados dos bairros Luizote de Freitas e Morumbi.

Muitos moradores afirmaram que a presença de policiais nas ruas do bairro, apesar de ser um fator positivo no combate da violência, não tem sido suficiente para inibir o crime. Outros, por sua vez, disseram que têm medo de andar no bairro à noite, sobretudo porque é predominantemente neste período que os criminosos atuam.

Foi possível constatar, entre os moradores entrevistados, certa apreensão, incômodo, descontentamento e medo em relação a determinadas perguntas realizadas. Eram comuns narrativas em que o tom de voz mudava ou diminuía de intensidade, como se estivessem revelando um segredo que não poderia ser ouvido por outros. Observou-se, também, que as falas eram carregadas de dor e falta de esperança, marcadas pela sensação de impotência perante o crescimento da violência e da insegurança.

Constatou-se que a sensação de segurança entre os moradores cresce à medida que os policiais estão circulando pelo bairro. Mas segurança não se faz apenas com a presença de policiais; e é por isso que diversos programas e projetos vêm sendo implementados em Uberlândia, como: o Centro de pesquisa e extensão em violência e políticas de segurança; Jovens Construindo Cidadania (JCC); Reestruturação dos Postos Integrados de Segurança e Cidadania (PISC); Projeto vídeo-monitoramento "Olho Vivo"; Projeto Anjos na escola; Programa educacional de resistência às drogas e à violência (PROERD); Projeto Garoto do Futuro, dentre outros.
Além desses projetos e programas supracitados, acrescenta-se o Sistema Olho Vivo, o Programa Fica Vivo e o Grupo Especializado em Áreas de Risco (GEPAR), que também vêm atuando em Uberlândia com o objetivo de prevenir e controlar a criminalidade. Ressalta-se que o Programa de Integração da Polícia também tem permitido uma melhor atuação na prevenção da criminalidade, bem como na resolução de questões diretamente ligadas a ela, já que nele é possível manter certa interlocução entre polícia militar e civil. (CROVATO, 2009).

É importante lembrar que tanto o Estado quanto a sociedade civil devem desenvolver ações preventivas, para que a vitimização diminua. Santos (1999, p. 17) comenta que "[...] o primeiro passo é a busca do entendimento do contexto onde a violência acontece e a identificação de áreas onde estas situações compartilham uma dinâmica particular. Só a partir desse conhecimento será possível realizar o planejamento de ações específicas”.

Violência e medo são dois fenômenos interligados, e ambos aumentam de forma proporcional. Um fator que contribui para o crescimento do medo da violência entre a população é a falta de punição dos infratores. $\mathrm{O}$ aumento das práticas criminais ocorre, principalmente porque os criminosos quando são presos contam com diversos recursos na Justiça; e quando não o são, continuam nas ruas fazendo mais vítimas.

Apesar da localização periférica, os bairros Luizote de Freitas e Morumbi apresentam perfis socioeconômico, períodos históricos de surgimento, estruturação interna e indicadores de criminalidade diferenciados. No entanto, os morados apresentam percepção e discursos sobre a violência bastante parecidos, confirmando a proposição de alguns autores sobre a generalização e banalização da violência como algo "natural" e inerente a sociedade urbana contemporânea.

O bairro Morumbi, vem se consolidando como um importante território da violência em Uberlândia, e, por conseguinte, estigmatizado no 
Percepção espacial da violência e do medo pelos moradores dos bairros Morumbi e Luizote de Freitas em Uberlândia/MG Márcia Andréia Ferreira Santos, Julio Cesar de Lima Ramires

conjunto da cidade, tanto por seus moradores, como os residentes de outros bairros. O assassinato do presidente da associação de morados em março de 2009, e a permanência constante do policiamento militar nos principais acessos ao bairro, confirmam a gravidade da violência nesse bairro.

A análise da territorialização da violência no espaço urbano, incorporando a visão dos morados que vivenciam esse problema cotidianamente, pode ampliar o quadro de análise dos estudos geográficos sobre esse tema, procurando não se restringir apenas à espacialização das ocorrências criminais.

Para implantar políticas de segurança é necessária a identificação dos espaços nos quais a violência produz mais vítimas e a visão da população sobre esse processo. A partir daí, as políticas de segurança devem trabalhar de forma a conhecer as possíveis causas dos crimes e, então, elaborar estratégias que minimizem o impacto da violência neste espaço. Isso deve ser feito levando-se em consideração que um mesmo crime pode ocorrer em diferentes espaços da cidade, mas não necessariamente as suas causas serão as mesmas. Daí a importância em se buscar conhecer os diferentes territórios da violência para que as políticas empreendidas tenham eficácia.

\section{Referências}

ARAUJO SOBRINHO, F. L. Evolução urbana e moradia popular em Uberlândia-MG: estudo de caso do Santa Mônica. 1995. 138f. Monografia (Graduação em Geografia) - Universidade Federal de Uberlândia, Uberlândia, 1995.

ARENDT, H. Da violência. Brasília: Editora da Universidade de Brasília, 1985. 67p.

BAIERL, L. F. Medo social: Da violência visível ao invisível da violência. São Paulo: Cortez, 2004. 224p.

CALDEIRA, T. P. do R. Enclaves fortificados: a nova segregação urbana. Novos estudos Cebrap, São Paulo, n.47, p.155-176, mar./ 1997.
Cidade de muros: crime, segregação e cidadania em São Paulo. São Paulo: Ed.34/ EDUSP, 2003. $399 \mathrm{p}$.

CARDIA, N. Exposição à violência: seus efeitos sobre valores e crenças em relação a violência, polícia e direitos humanos. Revista Lusotopie, p. 299-328, 2003.

CARLOS, A. F. A. O espaço urbano: novos escritos sobre a cidade. São Paulo: Contexto, 2004. 154 p.

CERTEAU, M. de; GIARD, L.; MAYOUL, P. $A$ invenção do cotidiano: morar, cozinhar. Petrópolis, RJ: 1996. 372p.

CHESNAIS, J. C. A Violência no Brasil. Causas e recomendações políticas para a sua prevenção. Ciência \& Saúde Coletiva, Rio de Janeiro, n.1, p.5369, 1999.

CHRISTOFOletTI, A. Perspectivas da Geografia. São Paulo: Difel, 1982, 318p.

CROVATO, D. Paranaíba Cidades. Entrevistador: Guy Boaventura. Uberlândia: TV Paranaíba, 25 jan. 2009. Entrevista concedida no programa de televisão "Paranaíba Cidades".

FEIGUIN, D.; LIMA, R. S. de. Tempo de violência: medo e insegurança em São Paulo. São Paulo em Perspectiva, São Paulo, v.9, n.2, p. 73-80, abr.jun. 1995.

FELIX, A. F. Geografia do crime: interdisciplinaridade e relevâncias. Marília: UNESP, 2002. 149 p.

Geografia do Crime de Marília/SP: Aspectos da violência e criminalidade em uma cidade média brasileira. In: SEMINÁRIO INTERNACIONAL DE ESTUDOS URBANOS, 4.

2003, Buenos Aires. Resumos... Buenos Aires, 2003. CD-ROM.

FRANCISCO FILHO, L. L. Distribuição espacial da 
Percepção espacial da violência e do medo pelos moradores dos bairros Morumbi e Luizote de Freitas em Uberlândia/MG Márcia Andréia Ferreira Santos, Julio Cesar de Lima Ramires

violência em Campinas: uma análise por geoprocessamento. 2004. $170 \mathrm{fl}$. Tese (Doutorado em Geografia) - Instituto de Geociências - Departamento de Geografia, Universidade Federal do Rio de Janeiro, Rio de Janeiro, 2004.

GIL, A. C. Entrevista. In: . Métodos e técnicas de pesquisa social. São Paulo: Atlas, 1999. p. 117126.

LOPEZ, M. V. et al. Muertes por homicidio, consecuencia fatal de la violencia. El caso de México, 1979-1992. Revista de Saúde Pública, São Paulo, v. 30, p.46-52, 1995.

MELGAÇO, L. de M. A Geografia do Atrito: Dialética espacial e violência em Campinas-SP. 2005. 142f. Dissertação (Mestrado em Geografia)Faculdade de Filosofia, Letras e Ciências Humanas, Universidade de São Paulo, São Paulo, 2005.

MORAIS, R. O que é violência urbana. São Paulo: Brasiliense, 1990. 113p.

OLIVEIRA, A. P. Medo da violência pode provocar síndrome do pânico e hipertensão. Folha Online, 25 de novembro de 2004.

PEDRAZZINI, Y. A violência das cidades. Petrópolis, RJ: Editora Vozes, 2006. 188p.

SANTOS, S. M. Homicídios em Porto Alegre, 1996: análise ecológica de sua distribuição e contexto socioespacial. 1999. 126 fl. Dissertação (Mestrado em Saúde Pública) - Escola Nacional de Saúde Pública, Fundação Oswaldo Cruz, Rio de Janeiro, 1999.

SILVEIRA, A. M. Prevenindo homicídios: Avaliação do Programa Fica Vivo no Morro das Pedras em Belo Horizonte. 2007. 290f. Tese (Doutorado em Ciências Humanas - Sociologia e Política) - Faculdade de Filosofia e Ciências Humanas, Universidade Federal de Minas Gerais, Belo Horizonte, 2007.
SOARES, B. R. Habitação e produção do espaço de Uberlândia. 1988. 195 fl. Dissertação (Mestrado em Geografia) - Faculdade de Filosofia, Letras e Ciências Humanas, Universidade de São Paulo, São Paulo, 1988.

SOARES, B. R.; MOURA, G. G. Reconfigurações urbanas do bairro Luizote de Freitas. Revista Sociedade Natureza, Uberlândia, Ano 12, n. 23, p. 23-38, 2000.

SOUZA, M. L. de. Fobópole: o medo generalizado e a militarização da questão urbana. Rio de Janeiro: Bertrand Brasil, 2008. 288p.

SORIANO, E. Os espaços de medo e os de castigo nas pequenas cidades do estado de São Paulo: o caso Itirapina. 2007. 157f. Dissertação (Mestrado em Geografia)-Instituto de Geociências e Ciências Exatas, Universidade Estadual Paulista, Rio Claro, 2007.

TEIXEIRA, M. C. S.; PORTO, M. do R. S. Violence, unsecurity and "imaginary of fear". Caderno CEDES, Campinas, v.19, n.47, p. 51-66, dezembro, 1998.

TUAN, Y. F. Medo na cidade. In: Paisagens do medo. São Paulo: Editora UNESP, 2005. p. 231278.

Topofilia: um estudo da percepção, atitudes e valores do meio ambiente. São Paulo: Difel, 1988. 288 p.

. Espaço e lugar: a perspectiva da experiência. São Paulo: Difel, 1983. 250p.

VARELA, C. Que significa estar seguro? De delitos, miedos e inseguridades entre los adultos mayores. Cuadernos de Antropologia Social, Buenos Aires, n.22, jul./dez. 2005. 